\title{
Two Actions of Calcium Regulate the Supply of Releasable Vesicles at the Ribbon Synapse of Retinal Bipolar Cells
}

\author{
Ana Gomis, Juan Burrone, and Leon Lagnado \\ Medical Research Council Laboratory of Molecular Biology, Cambridge CB2 2QH, United Kingdom
}

Ribbon synapses of sensory neurons are able to sustain high rates of exocytosis in response to maintained depolarization, but it is not known how this is achieved. Using the capacitance technique, we have found that $\mathrm{Ca}^{2+}$ regulates the supply of releasable vesicles at the ribbon synapse of depolarizing bipolar cells from the retina of goldfish. $\mathrm{Ca}^{2+}$ had two actions that could be differentiated by introduction of the $\mathrm{Ca}^{2+}$ chelator EGTA; one action stimulated refilling of the rapidly releasable pool of vesicles from a reserve pool, and a second action stimulated recruitment of vesicles to the reserve pool. The capacity of the reserve pool was $\sim 3500$ vesicles, which is similar to the number that can attach to the ribbons. These results suggest that continuous exocytosis at ribbon synapses is maintained by the $\mathrm{Ca}^{2+}$-dependent translocation of vesicles from the cytoplasm, through the ribbon, to release sites on the plasma membrane.

Key words: synapse; vesicle; calcium; exocytosis; refilling; synaptic depression; retina; depolarizing bipolar cell; ribbon synapse; EGTA
The processes that make synaptic vesicles available for exocytosis play an important role in determining the efficiency of synaptic transmission during ongoing activity. For instance, many synapses exhibit short-term depression after a period of activity, and this is at least partly because of a decrease in the number of rapidly releasable vesicles docked at the plasma membrane (Del Castillo and Katz, 1954; Betz, 1970; Zucker, 1989; Rosenmund and Stevens, 1996; Dittman and Regehr, 1998). The question of how vesicles become available for exocytosis is of particular importance at ribbon synapses, which can support continuous high rates of exocytosis in response to maintained depolarization (Dowling and Ripps, 1973; Parsons et al., 1994; Lagnado et al., 1996; Rieke and Schwartz, 1996). Ribbon synapses are found in sensory neurons that generate graded voltage signals rather than action potentials, including photoreceptors and bipolar cells in the retina (Gray and Pease, 1971; Rao-Mirotznik et al., 1995; von Gersdorff et al., 1996) and auditory and vestibular hair cells in the ear (Jacobs and Hudspeth, 1990; Lenzi et al., 1999). Electron micrographs of these neurons show that the regions in which synaptic vesicles dock to the plasma membrane are associated with an electron-dense structure, called a ribbon or synaptic body, to which vesicles attach by short filaments. This arrangement suggests that vesicles attached to the ribbon form a reserve pool that supplies the active zone on the plasma membrane (Gray and Pease, 1971), although it has been difficult to test this idea experimentally (Burns and Augustine, 1995; Lenzi et al., 1999). Recently, our knowledge of the structure of ribbon synapses has been complemented by functional studies of exocytosis using capacitance and optical techniques. In particular, we have a relatively large amount of information about vesicle cycling at the ribbon synapse of depolarizing bipolar cells from the goldfish

\footnotetext{
Received March 19, 1999; revised May 13, 1999; accepted May 14, 1999.

A.G. was supported by the European Community. We thank Guilherme Neves for helpful discussions.

Correspondence should be addressed to Leon Lagnado, Medical Research Council Laboratory of Molecular Biology, Hills Road, Cambridge CB2 2QH, UK.

Copyright (C) 1999 Society for Neuroscience $0270-6474 / 99 / 196309-09 \$ 05.00 / 0$
}

retina (Tachibana et al., 1993; Heidelberger et al., 1994; von Gersdorff and Matthews, 1994; Lagnado et al., 1996). An important feature of this synapse is that the size of the rapidly releasable pool of vesicles (RRP) can be directly measured using the capacitance technique (Mennerick and Matthews, 1996; Neves and Lagnado, 1999).

We have investigated the refilling of the RRP in goldfish bipolar cells during different patterns of stimulation and after introduction of the $\mathrm{Ca}^{2+}$ chelator EGTA. Our results indicate that $\mathrm{Ca}^{2+}$ entering through $\mathrm{Ca}^{2+}$ channels has two effects that stimulate the supply of vesicles to the RRP. Over the short-term, $\mathrm{Ca}^{2+}$ stimulated refilling of the RRP from a reserve pool, and over the long-term, $\mathrm{Ca}^{2+}$ stimulated the recruitment of vesicles to the reserve pool. The ability of residual $\mathrm{Ca}^{2+}$ to stimulate refilling of the RRP for periods of 5-10 sec indicates that this action occurs at free $\mathrm{Ca}^{2+}$ concentrations in the range of $1 \mu \mathrm{M}$ or below. The capacity of the reserve pool was estimated to be $\sim 3500$ vesicles, which is similar to the total number attached to the ribbons, calculated from serial EM reconstructions (von Gersdorff et al., 1996). These results therefore provide functional evidence for the idea that the ribbon acts to supply vesicles to the active zone on the plasma membrane. $\mathrm{Ca}^{2+}$-dependent trafficking of vesicles through the ribbon to the RRP may act to maintain high rates of exocytosis that occur during maintained depolarizing responses (Lagnado et al., 1996; Rouze and Schwartz, 1998; Neves and Lagnado, 1999).

\section{MATERIALS AND METHODS}

Isolated synaptic terminals of depolarizing bipolar cells from the goldfish retina were obtained by enzymatic dissociation (Burrone and Lagnado, 1997). Terminals were voltage-clamped using the perforated patch technique, and capacitance measurements were made using the piecewise linear method (Neher and Marty, 1982). Our implementation of this method is described by Neves and Lagnado (1999). Briefly, a sinusoidal command voltage $(50 \mathrm{mV}$ peak-to-peak, $2 \mathrm{kHz}$ ) was superimposed onto a holding potential of $-70 \mathrm{mV}$. The output of the patch-clamp amplifier was analyzed by a two-phase lock-in amplifier, the phase of which was set using the "capacitance dither" technique, allowing independent measurement of changes in membrane capacitance and conductance (Gillis, 
1995). The capacitance signal was calibrated by dithering the capacitance by $100 \mathrm{fF}$ at the beginning of the recording episode. The change in capacitance elicited by the stimulus $\left(\Delta C_{\mathrm{m}}\right)$ was measured by subtracting the capacitance signal before the stimulus from that measured after. The "before" measurement was averaged over a period of 50-300 msec, ending $20 \mathrm{msec}$ before depolarization. The "after" measurement was averaged over a period of 50-300 msec, beginning $20 \mathrm{msec}$ after repolarization.

The capacity of the RRP was measured after various stimulation patterns by measuring the capacitance increase elicited by a $20 \mathrm{msec}$ depolarization to $0 \mathrm{mV}$. At this potential, the $\mathrm{Ca}^{2+}$ current is maximally activated. A $20 \mathrm{msec}$ stimulus was sufficient to ensure that the whole of the RRP was exhausted, because it is normally released with a time constant of 2-4 msec (see Results). This duration stimulus also provided a safety margin that ensured depletion of the RRP when the $\mathrm{Ca}^{2+}$ current was partially inactivated, as sometimes occurred immediately after the introduction of a large $\mathrm{Ca}^{2+}$ load by prolonged depolarization.

The standard Ringer's solution contained (in mM): $120 \mathrm{NaCl}, 2.5$ $\mathrm{CaCl}_{2}, 2.5 \mathrm{KCl}, 1 \mathrm{MgCl}_{2}, 10$ glucose, and $10 \mathrm{HEPES}, \mathrm{pH}$ 7.3. The solution in the patch pipette contained (in $\mathrm{mM}$ ): 110 caesium gluconate, $4 \mathrm{MgCl}_{2}, 3 \mathrm{Na}_{2} \mathrm{ATP}, 1 \mathrm{Na}_{2} \mathrm{GTP}, 10$ TEACl, 0.4 BAPTA, and 20 HEPES, with $250 \mu \mathrm{g} / \mathrm{ml}$ nystatin (260 mOsm/l, pH 7.2).

In some experiments terminals were loaded with the $\mathrm{Ca}^{2+}$ chelator EGTA by incubation in 0.1 or $0.2 \mathrm{~mm}$ EGTA-AM (0.1\% DMSO; Molecular Probes, Eugene, OR) for 15-20 min.

All measurements are given as mean \pm SEM.

\section{RESULTS}

\section{Measuring the rapidly releasable pool of vesicles}

In depolarizing bipolar cells, there is a clear kinetic distinction between the first and second phases of exocytosis elicited by strongly activating the $\mathrm{Ca}^{2+}$ current (Mennerick and Matthews, 1996; Neves and Lagnado, 1999). Here, we define the pool of vesicles involved in the first phase as the RRP. The approach we used to measure the size of the RRP is derived from the behavior shown in Figure 1. Figure $1 A$ shows the capacitance response to two pairs of depolarizing stimuli to $-10 \mathrm{mV}$, a potential at which the $\mathrm{Ca}^{2+}$ current is maximally activated. The interval between the stimuli was $100 \mathrm{msec}$. The duration of the first stimulus was varied between 0.5 and $20 \mathrm{msec}$ so as to release a varying proportion of the RRP. These responses are plotted as the filled circles in Figure $1 B$. In this example, the maximum amplitude of the first phase of exocytosis was $45 \mathrm{fF}$, equivalent to $\sim 1700$ vesicles, assuming the capacitance of a single vesicle is $26 \mathrm{aF}$ (Neves and Lagnado, 1999). The RRP was exhausted with a time constant of $4 \mathrm{msec}$, so a $20 \mathrm{msec}$ depolarization was more than sufficient to release all of it. Here, we term a $20 \mathrm{msec}$ depolarization to a potential that maximally activates the $\mathrm{Ca}^{2+}$ current $(-10$ or $0 \mathrm{mV})$ the "emptying" stimulus, and we used it to probe the size of the RRP after various patterns of stimulation.

Evidence that this approach does indeed measure changes in the size of the RRP is shown in Figure $1 B$ in which the open circles plot the response to the emptying stimulus applied after variable amounts of the RRP were released. The decline in the measured size of the RRP mirrored the amount of rapid exocytosis elicited by the first stimulus. The dashed line shows the time course over which the RRP was expected to decline, assuming that the RRP was equivalent to $45 \mathrm{fF}$ at the start of each trial and that there was negligible refilling in the $100 \mathrm{msec}$ period between stimuli. The decline in the measured size of the RRP mirrored the amount of rapid exocytosis elicited by the first stimulus in similar experiments on eight other cells.

\section{Refilling of the RRP after a brief stimulus}

To assess how the RRP was refilled after a brief stimulus, two emptying stimuli were applied with varying delays, as shown in Figure $2 A$. After a delay of $100 \mathrm{msec}$, there was only a small
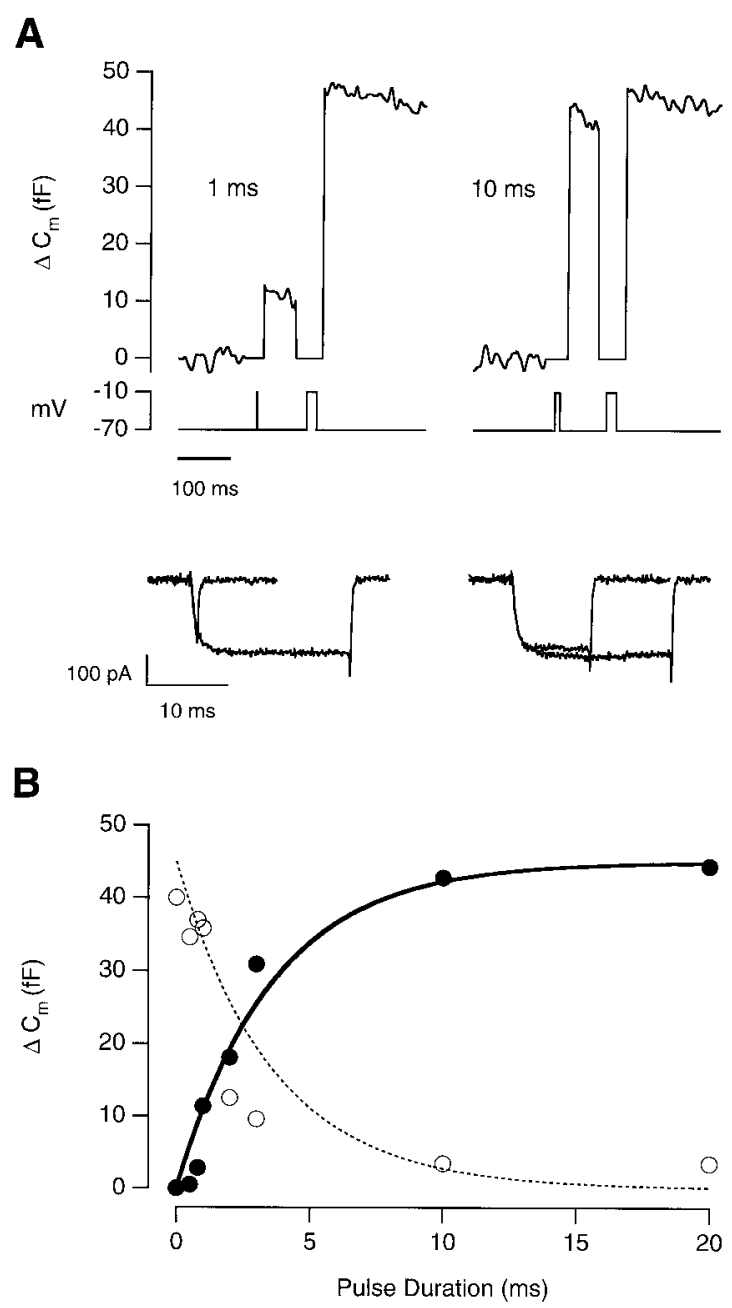

Figure 1. Measuring the rapidly releasable pool of vesicles. A, Capacitance increases elicited by a double-pulse protocol. The first depolarization from -70 to $-10 \mathrm{mV}$ lasted $1 \mathrm{msec}$ in the example on the left and 10 msec in the example on the right. In each case, the second stimulus was a $20 \mathrm{msec}$ depolarization, delivered after a delay of $100 \mathrm{msec}$, to release the remainder of the RRP (the emptying stimulus). The rest period between stimulation episodes was 1-3 min. The size of the RRP at the beginning of each stimulus episode was equivalent to a total response of $\sim 45 \mathrm{fF}$. The $\mathrm{Ca}^{2+}$ currents are shown below. $B$, The capacitance increase elicited by the first stimulus plotted as a function of its duration ( filled circles). The bold line through the points is a saturating exponential with a time constant of $3.6 \mathrm{msec}$ and a maximum amplitude of $45 \mathrm{fF}$. The open circles plot the capacitance increase elicited by the emptying stimulus. The dashed line is a mirror image of the bold line (see Results).

response to the second stimulus (Fig. 2A, top left), averaging 6\% of the first. The $\mathrm{Ca}^{2+}$ currents flowing during each stimulus were very similar (Fig. $2 A$, inset), so depression of the second response was not a result of inactivation of the $\mathrm{Ca}^{2+}$ current. As the interval between stimuli was increased, the second response recovered, reflecting refilling of the RRP (Fig. $2 A$, middle, right). Results from this type of experiment are collected in Figure $2 B$, which plots the refilling of the RRP as a function of the interval between stimuli. There were two phases of refilling: $30 \%$ of the RRP was refilled with a time constant of $0.64 \mathrm{sec}$, and the remainder with a time constant of $31 \mathrm{sec}$.

Behavior qualitatively similar to that shown in Figure 2 has also been observed at synapses from the CNS of mammals in which there are fast and slow phases of recovery from synaptic depres- 
A

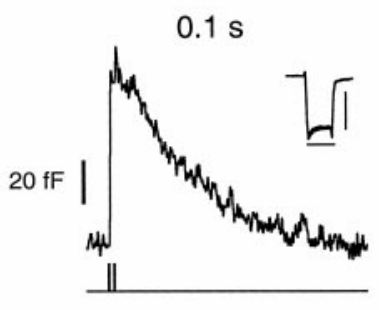

$3 \mathrm{~s}$

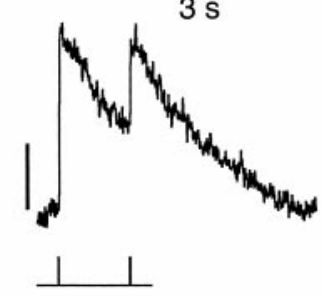

B

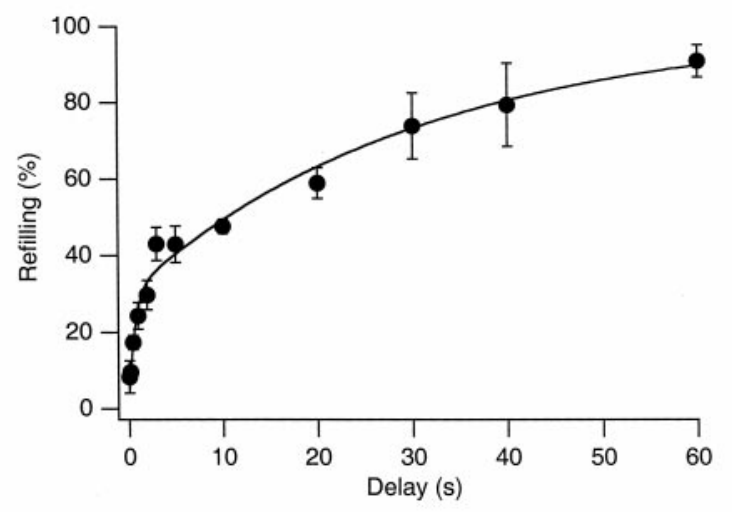

$40 s$

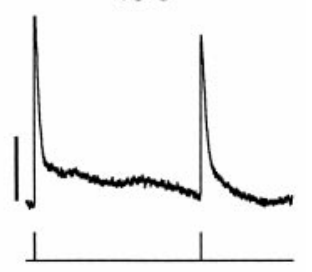

Figure 2. Refilling of the RRP after complete depletion by a $20 \mathrm{msec}$ stimulus. $A$, The capacitance response to two $20 \mathrm{msec}$ depolarizations is shown for intervals of $100 \mathrm{msec}$ (left), $3 \mathrm{sec}$ (middle), and $40 \mathrm{sec}$ (right). In each case, the stimulus was a depolarization from -70 to $0 \mathrm{mV}$. The inset in the left panel is a superimposition of the $\mathrm{Ca}^{2+}$ currents elicited by two stimuli (calibration: $20 \mathrm{msec}, 200 \mathrm{pA}$ ). Currents were leak subtracted using a single leak pulse (a $20 \mathrm{mV}$ depolarization from $-70 \mathrm{mV}$ ). $B$, The time course of refilling of the RRP measured from the type of experiment shown in $A$. The amplitude of the second response is expressed as a percentage of the first for various intervals. The line fitted through the points is a double-exponential, with $30 \%$ of sites refilled with a time constant of 0.64 $\mathrm{sec}$ and the remainder with a time constant of 31 sec. The number of observations for each interval are as follows: $100 \mathrm{msec}, 7 ; 250 \mathrm{msec}, 1 ; 500 \mathrm{msec}$, 24; $1 \mathrm{sec}, 14 ; 2 \mathrm{sec}, 13 ; 5 \mathrm{sec}, 20 ; 10 \mathrm{sec}, 10 ; 20 \mathrm{sec}$, 4; $30 \mathrm{sec}, 3 ; 40 \mathrm{sec}, 3 ; 60 \mathrm{sec}, 3$. sion. The fast phase can be inhibited by the $\mathrm{Ca}^{2+}$ chelator EGTA, indicating that it reflects the transient acceleration of refilling by residual $\mathrm{Ca}^{2+}$ (Dittman and Regehr, 1998; Stevens and Wesseling, 1998; Wang and Kaczmarek, 1998). Below, we present evidence that residual $\mathrm{Ca}^{2+}$ also stimulates refilling of the RRP in the synaptic terminal of bipolar cells. However, at this ribbon synapse, $\mathrm{Ca}^{2+}$ appears to stimulate refilling of the RRP by two actions, one of which is more sensitive to EGTA.

\section{Refilling of the RRP was stimulated by calcium}

When the duration of the depolarizing stimulus was increased, refilling of the RRP was accelerated above the basal rate for a longer period. The protocol used to measure refilling after a longer stimulus is shown in Figure $3 A$, Test. First, the emptying stimulus was applied to measure the initial size of the RRP. Next, a $500 \mathrm{msec}$ depolarization to $0 \mathrm{mV}$ was delivered after a delay of $200 \mathrm{msec}$. Finally, the emptying stimulus was applied again to measure the RRP after a variable delay. In the example shown in Figure $3 A, 91 \%$ of the RRP was refilled $10 \mathrm{sec}$ after a $500 \mathrm{msec}$ depolarization (Test), but only $\sim 44 \%$ was refilled $10 \mathrm{sec}$ after the emptying stimulus delivered alone (Control). The time course of refilling after depolarizations lasting 20 (filled circles) and 500 (open circles) $\mathrm{msec}$ is compared in Figure $3 C$. The basal rate constant of refilling, measured from the slow phase after a brief stimulus, was $0.03 / \mathrm{sec}$ (Fig. $2 B$ ). Figure $3 C$ shows that after a 500 msec depolarization, refilling was accelerated above the basal rate for 5-10 sec until the RRP was almost completely replenished. In comparison, it took $\sim 60 \mathrm{sec}$ to refill $90 \%$ of the RRP after a 20 msec depolarization (Fig. 2B).

Although the net effect of a longer stimulus was to potentiate refilling of the RRP, at short delays the RRP was significantly smaller (Fig. $3 C$ ). For instance, in the example shown in Figure $3 B$ (same terminal as Fig. $3 A$ ), there did not appear to be any refilling of the RRP $1 \mathrm{sec}$ after a $500 \mathrm{msec}$ depolarization, whereas $\sim 19 \%$ was refilled $1 \mathrm{sec}$ after a $20 \mathrm{msec}$ depolarization. The delayed growth in the size of the RRP after a $500 \mathrm{msec}$ stimulus is probably because residual $\mathrm{Ca}^{2+}$ continued to stimulate exocytosis after closure of $\mathrm{Ca}^{2+}$ channels. Capacitance and optical measurements in bipolar cell terminals have demonstrated that residual $\mathrm{Ca}^{2+}$ can continue to drive exocytosis for periods of $1 \mathrm{sec}$ or more, at rates of 400-800 vesicles/sec (Neves and Lagnado, 1999). We would expect that vesicles accumulate in the RRP only after their removal by exocytosis has ceased, which can take $\sim 1 \mathrm{sec}$ after a $500 \mathrm{msec}$ depolarization to $0 \mathrm{mV}$. Consistent with the results in Figure $3 C$, exocytosis does not continue after a 20 msec stimulus that introduces a smaller amount of $\mathrm{Ca}^{2+}$ (Neves and Lagnado, 1999).

An idea of the changes in free cytoplasmic $\left[\mathrm{Ca}^{2+}\right]$ that occurred after stimulation could be obtained using $\mathrm{Ca}^{2+}$-activated conductances in the plasma membrane that are activated by residual $\mathrm{Ca}^{2+}$ and generate a slowly decaying tail current (Okada et al., 1995). Measurements of cytoplasmic $\left[\mathrm{Ca}^{2+}\right]$ have demonstrated that the amplitude of this current is correlated with the spatially averaged $\left[\mathrm{Ca}^{2+}\right]$, and it declines with a time constant that is similar to the fall in $\left[\mathrm{Ca}^{2+}\right]$ (Neves and Lagnado, 1999). Figure $4 A$ shows that the $\mathrm{Ca}^{2+}$-activated tail current was much larger and longer after a $500 \mathrm{msec}$ depolarization than after a 20 msec depolarization.

We tested whether residual $\mathrm{Ca}^{2+}$ might be the stimulus that accelerated refilling after a longer stimulus by loading terminals with the $\mathrm{Ca}^{2+}$ chelator EGTA so as to reduce the rise in cytoplasmic $\left[\mathrm{Ca}^{2+}\right]$. Terminals were loaded by incubation in the AM ester (see Materials and Methods). Buffering the rise in $\left[\mathrm{Ca}^{2+}\right]$ greatly reduced the $\mathrm{Ca}^{2+}$-activated tail current (Okada et al., 1995). This was most clearly observed after a $500 \mathrm{msec}$ depolarization (Fig. 4A,C), but it was also apparent after a $20 \mathrm{msec}$ depolarization that caused a small activation of the tail current (Fig. $4 B$ ). The tail current averaged $50 \pm 6$ pA $(n=20)$ immediately after a $500 \mathrm{msec}$ depolarization in a control terminal but only $10 \pm 2 \mathrm{pA}(n=12)$ after loading with EGTA. Experiments in which we have altered the internal concentration of $\mathrm{Ca}^{2+}$ buffers through a patch pipette indicate that at least $2 \mathrm{~mm}$ EGTA is required to cause a similar inhibition of the tail current (J. Burrone and L. Lagnado, unpublished observations; Okada et al., 1995).

EGTA shortened the accelerated phase of refilling that fol- 


\section{A 10 s delay}
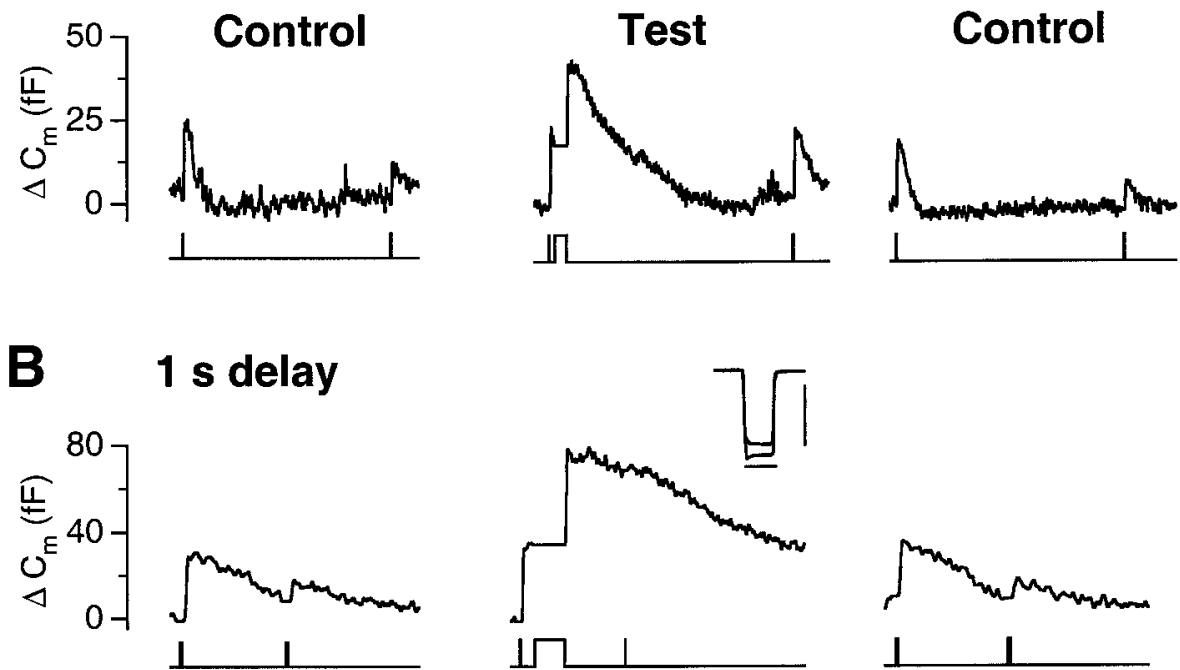

Figure 3. Refilling of the RRP after a long stimulus. $A$, Recovery of the capacitance response 10 sec after a $20 \mathrm{msec}$ depolarization (Control) is compared with that measured $10 \mathrm{sec}$ after a 500 msec depolarization (Test). Note that in the Test protocol, the $500 \mathrm{msec}$ stimulus was preceded by a $20 \mathrm{msec}$ depolarization to measure the initial size of the RRP. In this terminal, the RRP recovered $91 \%$ of its initial size $10 \mathrm{sec}$ after a 500 msec depolarization but only $44 \%$ in the controls immediately before and after. $B$, Recovery of the capacitance response $1 \mathrm{sec}$ after a $20 \mathrm{msec}$ depolarization is compared with that measured $1 \mathrm{sec}$ after a $500 \mathrm{msec}$ depolarization. In this terminal, the RRP did not exhibit any measurable recovery $1 \mathrm{sec}$ after the $500 \mathrm{msec}$ stimulus but recovered $17 \%$ in the control immediately before and $21 \%$ in the one after. The inset in the middle panel is a superimposition of the $\mathrm{Ca}^{2+}$ currents elicited by the two emptying stimuli (calibration: 20 msec, $200 \mathrm{pA}$ ). $C$, The time course of refilling of the RRP measured from the type of experiment shown in $A$ and $B$. The open circles show refilling measured after a $500 \mathrm{msec}$ depolarization; the amplitude of the response to the second depleting stimulus is expressed as a percentage of the first for various intervals. The open squares show results obtained in terminals loaded with EGTA (see Results and Fig. 5). The closed circles provide a comparison with the results in Figure $2 B$, showing refilling measured after a $20 \mathrm{msec}$ depolarization.

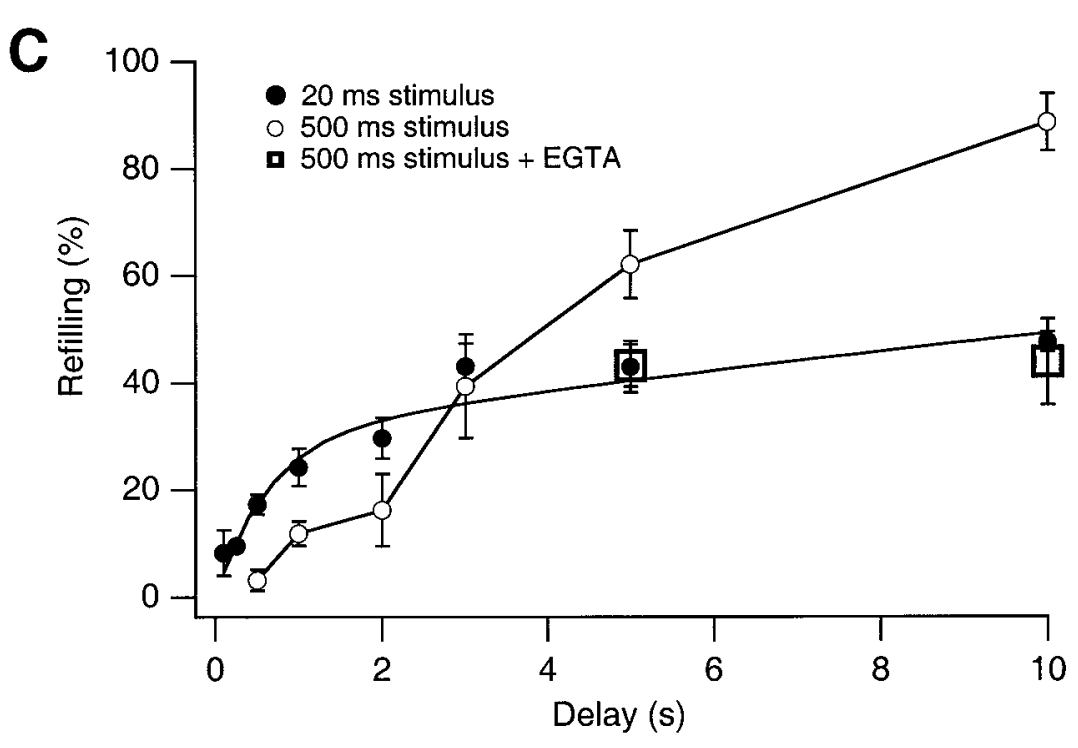

lowed a long stimulus. Examples of these measurements are shown in Figure $5 A$, and averaged results for delays of 10 and 5 sec are plotted as the open squares in Figure $3 C$ to allow a comparison with cells that did not contain any exogenous $\mathrm{Ca}^{2+}$ buffers. After a $500 \mathrm{msec}$ depolarization, the acceleration of refilling above its basal rate normally continued for $\sim 10 \mathrm{sec}$ (open circles), but buffering the rise in cytoplasmic $\left[\mathrm{Ca}^{2+}\right]$ blocked refilling at delays longer than $5 \mathrm{sec}$ (open squares). EGTA did not, however, block the initial accelerated phase of refilling. Figure $3 C$ shows that $43 \pm 4 \%$ of the RRP was refilled over the first $5 \mathrm{sec}$, although there was no further refilling over the next $5 \mathrm{sec}$. The refilling of $43 \%$ of the RRP in the first $5 \mathrm{sec}$ indicates an average rate constant of $0.09 / \mathrm{sec}$ over this period. In comparison, the basal rate constant of refilling was $0.03 / \mathrm{sec}$ in control terminals, as measured from the second phase of the double-exponential fit in Figure $2 B$. The initial rate constant of refilling in EGTA-loaded terminals was therefore at least three times that measured in control terminals at resting levels of $\mathrm{Ca}^{2+}$.

\section{The effects of EGTA on the first and second phases of exocytosis}

We compared the effects of EGTA on refilling of the RRP with its effects on the different kinetic components of exocytosis. EGTA had a small effect on exocytosis from the RRP. The first response to a 20 msec depolarization averaged $55.5 \pm 4.7 \mathrm{fF}(n=58)$ in control terminals and $40.6 \pm 3.6 \mathrm{fF}(n=38)$ in terminals loaded with EGTA (Fig. 5B). The somewhat smaller response in the presence of EGTA might reflect a slowing of exocytosis from the RRP and/or a decrease in the initial size of the pool. The latter possibility seems more likely because the kinetics of fast exocytosis are little affected by EGTA (Mennerick and Matthews, 1996), whereas EGTA inhibited refilling of the RRP over long time scales (see below). Our estimate of the initial size of the RRP in EGTA-loaded terminals is therefore likely to be a lower limit, especially in view of the fact that isolated bipolar cell terminals can spontaneously depolarize, triggering exocytosis 
A

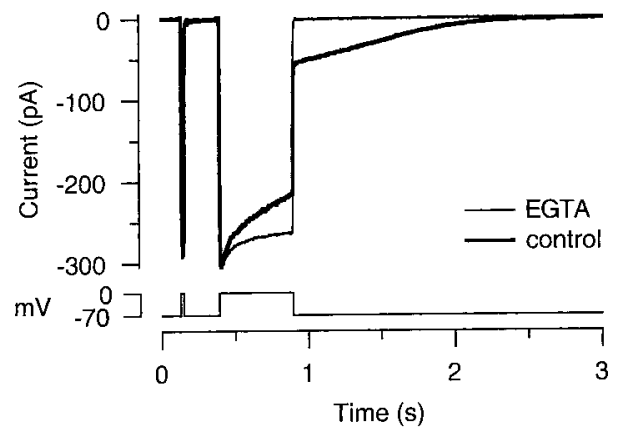

B
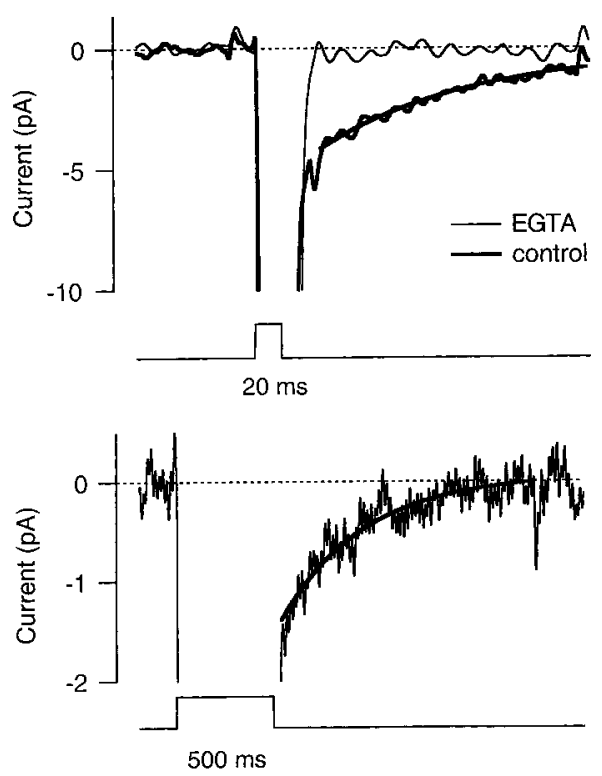

Figure 4. The rise in cytoplasmic $\left[\mathrm{Ca}^{2+}\right]$ was reduced in terminals loaded with EGTA. $A$, A comparison of the currents elicited by a 20 and $500 \mathrm{msec}$ depolarization from -70 to $0 \mathrm{mV}$ in a terminal with endogenous $\mathrm{Ca}^{2+}$ buffers (bold line) and a terminal additionally loaded with EGTA (thin line). These terminals were used for this comparison because the $\mathrm{Ca}^{2+}$ currents were of similar amplitude. EGTA blocked the $\mathrm{Ca}^{2+}$ activated tail current that decayed slowly after the $500 \mathrm{msec}$ stimulus. The latter part of the decay in the tail current occurred with a time constant of $0.51 \mathrm{sec}$ in the control. $B$, The tail currents after the $20 \mathrm{msec}$ stimuli shown on expanded scales. The bold line fitted to the control trace has a time constant of $0.11 \mathrm{sec}$. $C$, EGTA did not completely block the $\mathrm{Ca}^{2+}$. activated tail current after a $500 \mathrm{msec}$ stimulus; expansion of trace in $A$. The bold line fitted to the trace has a time constant of $0.43 \mathrm{sec}$.

(Burrone and Lagnado, 1997). In an effort to ensure that estimates of the size of the RRP were made before exocytosis had been stimulated to any appreciable extent, cells were loaded with EGTA in the absence of external $\mathrm{Ca}^{2+}$, and $\mathrm{Ca}^{2+}$ was replaced only after $\mathrm{Ca}^{2+}$ channels were held closed by voltage-clamping the terminal.

EGTA had a stronger inhibitory effect on the second, slower, phase of exocytosis. Figure $5 A$ compares responses to a 20 and $500 \mathrm{msec}$ stimulus, first under control conditions and then in a terminal loaded with EGTA. Considering only the first stimulus episode in a given terminal, a $500 \mathrm{msec}$ depolarization normally released $1.56 \pm 0.24(n=22)$ times as many vesicles as the preceding emptying stimulus. However, after loading with EGTA, this ratio was reduced to $0.73 \pm 0.17(n=10)$ (Fig. $5 C)$. We propose that these two actions of EGTA, inhibition of the second phase of exocytosis and reduced refilling after a long stimulus, reflects the involvement of the same set of vesicles, which undergo $\mathrm{Ca}^{2+}$-dependent transfer to the RRP (see Discussion).

\section{Recruitment to a reserve pool was stimulated by calcium}

To investigate refilling over longer time scales, the RRP was repeatedly exhausted by delivering trains of emptying stimuli at a frequency of $0.1 \mathrm{~Hz}$ for durations of $3 \mathrm{~min}$ or more. The second response in a train normally released $40-50 \%$ as many vesicles as the first (Fig. 6A,B), as would be expected from the results obtained with a double-pulse protocol (Fig. $2 B$ ). The amplitude of the capacitance response elicited by the emptying stimulus then remained constant, indicating that the same fraction of the RRP was refilled after each emptying stimulus and that the average rate of refilling was fixed (Fig. 6 $A$ ). The cumulative response during these stimulus trains, relative to the initial size of the RRP, is plotted as the filled circles in Figure $6 C$. The first response averaged $50 \pm 15 \mathrm{fF}(n=18)$. The RRP could be refilled at least ten times over, equivalent to the transfer of at least 20,000 vesicles, without any apparent depletion of the reservoir from which it was supplied.

When terminals were loaded with EGTA, the rate of refilling was not affected at first, because the second response was still $\sim 50 \%$ of the first (Fig. $6 A, B$ ). Thus, EGTA did not directly affect the transfer of vesicles to the RRP after a brief stimulus. Over the long term, however, the rate of refilling gradually declined during a train, until no more vesicles could be transferred to the RRP and the capacitance response was abolished (Fig. 6A,B). The cumulative response during these stimulus trains is plotted as the open circles in Figure $6 C$. In the presence of EGTA, the maximum number of vesicles transferred to the RRP averaged 2.7 times its initial size, or $\sim 3500 \pm 400$ vesicles (the amplitude of the first capacitance response in this set of EGTA-loaded terminals was $33.4 \pm 3.5 \mathrm{fF} ; n=16$ ). In other words, only $\sim 3500$ vesicles could be rapidly transferred from a reserve pool to the RRP in a terminal loaded with EGTA. A simple explanation for this result is that refilling of the RRP occurs from a reserve pool, which has an initial capacity of $\sim 3500$ vesicles, and EGTA blocks the transfer of vesicles to this pool, causing it to gradually empty (see Discussion).

If EGTA inhibits refilling of the reserve pool by buffering $\mathrm{Ca}^{2+}$ transients, then it should be possible to overcome this effect by introducing a larger $\mathrm{Ca}^{2+}$ load into the terminal. A demonstration that this is the case is shown in Figure 7. In this experiment, both the RRP and reserve pool were completely exhausted by applying a train of emptying stimuli, as in Figure 6. After a 150 sec period of rest, application of the emptying stimulus elicited a response of only $2 \mathrm{fF}$, confirming that the RRP was refilled very slowly at resting levels of $\mathrm{Ca}^{2+}$. A larger number of vesicles were released by a $500 \mathrm{msec}$ depolarization, and refilling of the RRP was stimulated, as demonstrated by the much larger response to the emptying stimulus applied after a delay of $10 \mathrm{sec}$. Similar behavior was observed in four other terminals. These results provide further support for the idea that $\mathrm{Ca}^{2+}$ stimulates the transfer of vesicles to the reserve pool and then to the RRP.

\section{DISCUSSION}

Two basic observations indicate that $\mathrm{Ca}^{2+}$ stimulates refilling of the RRP in the synaptic terminal of depolarizing bipolar cells. First, accelerated refilling of the RRP was prolonged by introducing a larger $\mathrm{Ca}^{2+}$ load into the terminal (Fig. $3 C$ ), and this 
A

Figure 5. EGTA inhibited the second phase of exocytosis and the acceleration of refilling caused by a prolonged stimulus. $A$, Recovery of the capacitance response after a $500 \mathrm{msec}$ depolarization is compared in a terminal with endogenous $\mathrm{Ca}^{2+}$ buffers (left ) and a terminal additionally loaded with EGTA (right). In each case, the size of the RRP was measured after a delay of $10 \mathrm{sec}$. EGTA had two effects: a $500 \mathrm{msec}$ depolarization caused less exocytosis, and recovery of the RRP was reduced. $B$, EGTA caused a small reduction in the capacitance response to the emptying stimulus. Only the first response in each terminal was used for this comparison because EGTA inhibited refilling of the RRP over the long term (see Results). $C$, EGTA inhibited exocytosis from the second pool of vesicles. The capacitance response to a $500 \mathrm{msec}$ depolarization is shown relative to the response to the emptying stimulus delivered $200 \mathrm{msec}$ before. All measurements were made from terminals in which these were the first stimuli.
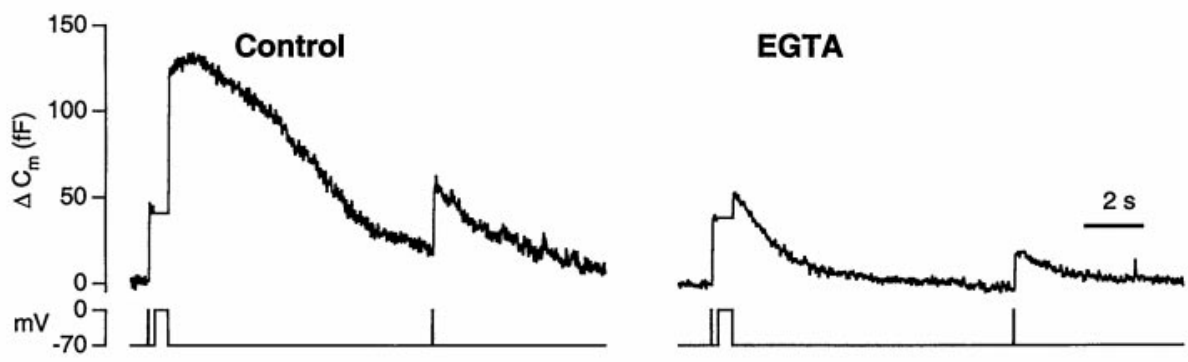

B

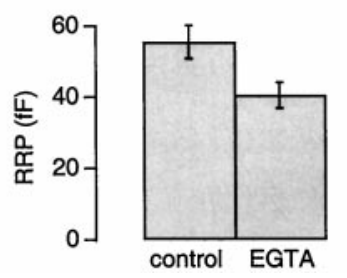

effect could be inhibited by buffering the rise in cytoplasmic $\left[\mathrm{Ca}^{2+}\right]$ with EGTA (Fig. 5). Second, EGTA limited the number of vesicles that could be released by repetitive brief stimuli (Fig. 6 ), and this effect could be counteracted by introducing a larger $\mathrm{Ca}^{2+}$ load into the terminal (Fig. 7).

\section{Vesicle pools in the bipolar cell terminal}

After brief depolarizations, EGTA blocked the $\mathrm{Ca}^{2+}$-dependent transfer of all but a small fraction of available vesicles, although it had no immediate effect on refilling of the RRP (Fig. 6). The differential action of EGTA allows us to provide a functional definition for two pools of vesicles involved in refilling of the RRP: a reserve pool of $\sim 3500$ vesicles that refills the RRP over the short term, and a much larger reservoir that maintains the supply of vesicles over the long term. Figure 8 shows a simple model of vesicle transfer in the bipolar cell terminal that seeks to integrate these results with previous anatomical and physiological work. Features of this model are discussed below.

It is possible to define at least three pools of vesicles in the bipolar cell terminal. When the $\mathrm{Ca}^{2+}$ current is activated maximally, the most rapid phase of exocytosis involves the release of 1200-1800 vesicles within $\sim 10 \mathrm{msec}$ (Heidelberger et al., 1994; Mennerick and Matthews, 1996; Neves and Lagnado, 1999). A similar number of vesicles are docked to the plasma membrane beneath the ribbon, suggesting that these correspond to the RRP (von Gersdorff et al., 1996). The second phase of exocytosis involves the release of $\sim 4400$ vesicles over $1 \mathrm{sec}$ (Neves and Lagnado, 1999). Two pieces of evidence indicate that these vesicles constitute the reserve pool that is used to refill the RRP after closure of $\mathrm{Ca}^{2+}$ channels. First, the reserve pool contained a similar number of vesicles, $\sim 3500$ (Fig. 6). Second, EGTA
Figure 6. EGTA inhibited refilling of a reserve pool of vesicles. $A$, Capacitance responses during a train of emptying stimuli (20 msec depolarizations to $0 \mathrm{mV}$ ) delivered at a frequency of 0.1 $\mathrm{Hz}$. The top is from a control terminal, and the bottom is from a terminal loaded with EGTA. The figures below the responses indicate the stimulus number in the train. $B$, Averaged results from the type of experiment shown in $A$. The capacitance responses during the stimulus train are plotted relative to the first response, which averaged $50 \mathrm{fF}$ in control terminals $(n=18$; closed symbols) and $33 \mathrm{fF}$ in terminals loaded with EGTA $(n=$ 16; open symbols). In control terminals, the second response was $45 \%$ of the first, and subsequent responses were not significantly different. In terminals loaded with EGTA, the response to the emptying stimulus gradually declined to zero. $C$, The accumulated amount of exocytosis averaged from the type of experiment shown in $A$. In control terminals, refilling of the RRP occurred at a constant average rate, as indicated by the solid line. In terminals loaded with EGTA, the maximum number of vesicles that could be transferred to the RRP was 2.7 times its initial size, as indicated by the dashed line.
A

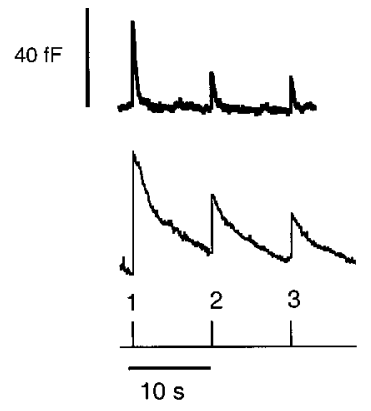

B

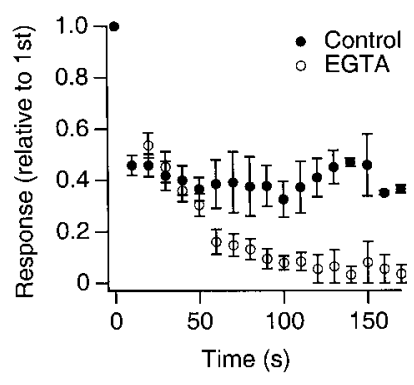

Control
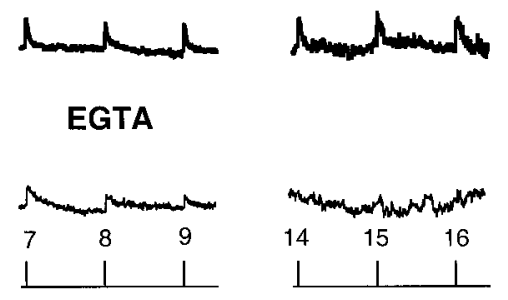

C

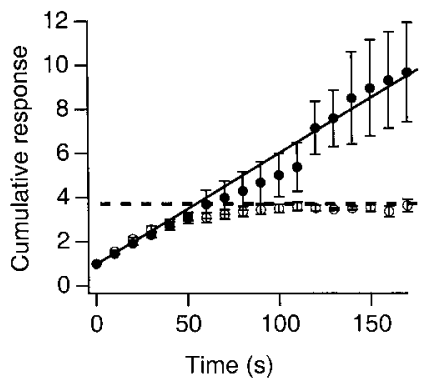




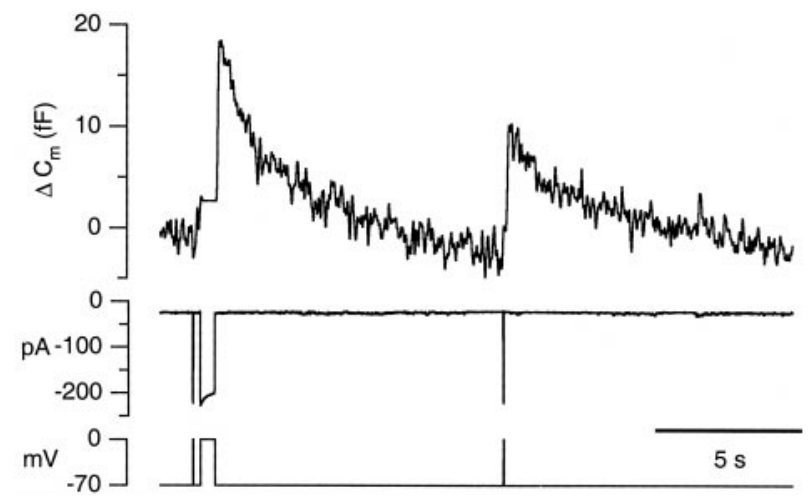

Figure 7. The effects of EGTA were partially overcome by introduction of a large $\mathrm{Ca}^{2+}$ load. Capacitance response from a terminal loaded with EGTA, after complete depletion of both the RRP and reserve pool by a train of stimuli. Before this stimulation episode, the terminal was at rest for $150 \mathrm{sec}$. The first emptying stimulus elicited a negligible response. A $500 \mathrm{msec}$ depolarization stimulated exocytosis and caused the RRP to refill, as demonstrated by the much larger response to the second emptying stimulus.

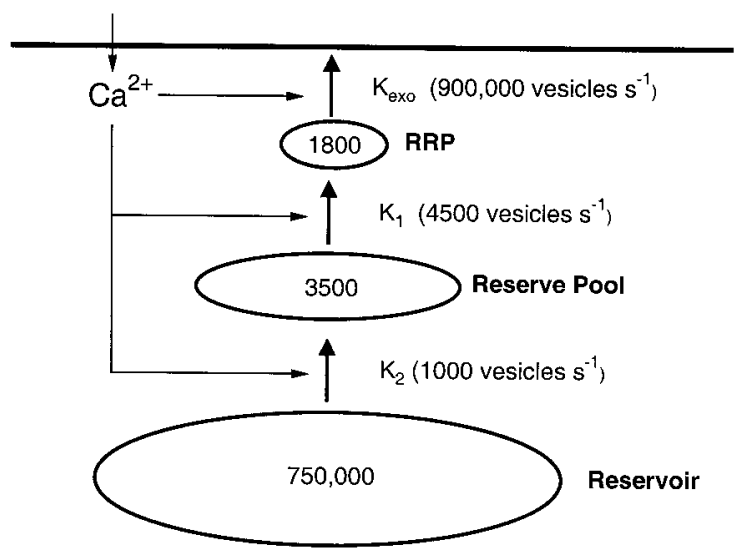

Figure 8. Vesicle pools in the synaptic terminal of depolarizing bipolar cells. Evidence for this model is summarized in Discussion. The numbers in parentheses indicate the rates of the vesicle transport when the $\mathrm{Ca}^{2+}$ current is maximally activated.

inhibited the second phase of exocytosis and also reduced refilling of the RRP stimulated by residual $\mathrm{Ca}^{2+}$ (Fig. 5). The anatomy of the bipolar cell terminal immediately suggests that the reserve pool of vesicles is attached to the ribbon behind the plasma membrane, and this idea is supported by EM measurements indicating that there are $\sim 4800$ vesicles attached to the ribbons (von Gersdorff et al., 1996). The third component of exocytosis observed during maintained depolarization occurs at a rate of $\sim 1000$ vesicles/sec but does not fatigue for periods of many tens of seconds (Lagnado et al., 1996; Rouze and Schwartz, 1998; Neves and Lagnado, 1999). Measurements made with FM1-43 indicate that this continuous process of exocytosis is supported by a reservoir of $\sim 750,000$ vesicles that is efficiently replenished by endocytosis (Lagnado et al., 1996). EM measurements indicate that there are a similar number of vesicles in the cytoplasm, free of the ribbons (von Gersdorff et al., 1996).

In the model shown in Figure 8, the rate constants $K_{1}$ and $K_{2}$ are both increased by $\mathrm{Ca}^{2+}$, but during brief periods of $\mathrm{Ca}^{2+}$ influx, EGTA is more effective at preventing the increase in $K_{2}$. When the $\mathrm{Ca}^{2+}$ current is activated maximally, the second phase of exocytosis occurs at a rate of $\sim 4500$ vesicles/sec (Neves and
Lagnado, 1999), so the maximum rate constant for the transfer of vesicles from the reserve pool to the RRP, $K_{1}$, is $\sim 1.3 / \mathrm{sec}$ (assuming the capacity of the reserve pool is 3500 vesicles). As might be expected, the rate of refilling that we measured after closure of $\mathrm{Ca}^{2+}$ channels was somewhat slower, occurring with a rate constant of $\sim 0.5 / \mathrm{sec}$ in the few hundred milliseconds after a $20 \mathrm{msec}$ depolarization (Fig. $2 B$ ). It appears that $\mathrm{Ca}^{2+}$ could modulate the rate of refilling over a range of $\sim 40$-fold, because the basal value of $K_{1}$ at resting levels of $\mathrm{Ca}^{2+}$ was $\sim 0.03 / \mathrm{sec}$ (Fig. $2 B$ ). After the first two pools of vesicles have been exhausted, continuous exocytosis occurs at a rate of $\sim 1000$ vesicles/sec (Neves and Lagnado, 1999), indicating that the maximum rate constant for the transfer of vesicles from the reservoir to the reserve pool, $K_{2}$, is $\sim 1.3 \times 10^{-3} / \mathrm{sec}$.

\section{Two actions of $\mathrm{Ca}^{2+}$}

The differential effect of EGTA on vesicle transfer to the RRP and reserve pool (Figs. 6, 7) might be explained if the $\mathrm{Ca}^{2+}$ binding molecule regulating $K_{2}$ was further from $\mathrm{Ca}^{2+}$ channels than the $\mathrm{Ca}^{2+}$-binding molecule regulating $K_{1}$. During brief periods of $\mathrm{Ca}^{2+}$ influx, the molecule regulating $K_{2}$ would be subject to smaller rises in $\left[\mathrm{Ca}^{2+}\right]$ that are more effectively buffered by EGTA (Neher, 1998).

The EGTA concentrations we introduced into the terminals were sufficient to strongly buffer $\mathrm{Ca}^{2+}$ at the $\mathrm{Ca}^{2+}$-dependent conductances in the plasma membrane (Fig. 4). Two factors might explain why they were not sufficient to inhibit refilling of the RRP after a brief stimulus (Fig. 6). First, the $\mathrm{Ca}^{2+}$-sensor for refilling may be closer to $\mathrm{Ca}^{2+}$ channels than the $\mathrm{Ca}^{2+}$ dependent conductances, so that it senses a larger rise in $\left[\mathrm{Ca}^{2+}\right]$ while $\mathrm{Ca}^{2+}$ channels are open. Second, the $\mathrm{Ca}^{2+}$-sensor for refilling may have a higher affinity for $\mathrm{Ca}^{2+}$ than the $\mathrm{Ca}^{2+}$ dependent conductances. The latter idea is supported by the observation that residual $\mathrm{Ca}^{2+}$ stimulated refilling for $\sim 10 \mathrm{sec}$ after a $500 \mathrm{msec}$ depolarization (Fig. $3 C$ ), whereas the $\mathrm{Ca}^{2+}$ activated tail current had decayed completely after 2 sec (Fig. 4). Neves and Lagnado (1999) used furaptra, a $\mathrm{Ca}^{2+}$-indicator of relatively low affinity, to measure the cytoplasmic $\left[\mathrm{Ca}^{2+}\right]$ in the bipolar cell terminal. Strongly activating the $\mathrm{Ca}^{2+}$ current for 1 sec caused the spatially averaged $\left[\mathrm{Ca}^{2+}\right]$ to reach $\sim 25 \mu \mathrm{M}$. After repolarization, the $\left[\mathrm{Ca}^{2+}\right]$ fell to undetectably low levels with a time constant of $\sim 0.7 \mathrm{sec}$, causing the $\mathrm{Ca}^{2+}$-activated tail current to decay similarly (Neves and Lagnado, 1999, their Fig. 10). Together, these measurements indicate that residual $\mathrm{Ca}^{2+}$ stimulated the transfer of vesicles at concentrations that did not activate $\mathrm{Ca}^{2+}$-dependent conductances at the plasma membrane and that were close to the limit of detection with furaptra. In the experiments of Neves and Lagnado (1999), it was quite possible to detect $\mathrm{Ca}^{2+}$ levels of $1.5 \mu \mathrm{M}$ with furaptra, so this figure provides an upper limit for the $\left[\mathrm{Ca}^{2+}\right]$ sufficient to stimulate the transfer of vesicles to the RRP.

\section{What is the relationship between transient and continuous exocytosis?}

Lagnado et al. (1996) and Rouze and Schwartz (1998) have demonstrated that continuous exocytosis at the bipolar cell synapse can be driven by $\mathrm{Ca}^{2+}$ concentrations of the order of $1 \mu \mathrm{M}$. Refilling of the RRP probably occurs at similar low levels of $\mathrm{Ca}^{2+}$, suggesting that continuous exocytosis might occur by the trafficking of vesicles from the bulk cytoplasm, through the reserve pool, to the RRP (Fig. 8). The initial rapid phase of exocytosis requires much higher levels of $\mathrm{Ca}^{2+}$; it is half- 
maximal at $\sim 200 \mu \mathrm{M} \mathrm{Ca}^{2+}$ (Heidelberger et al., 1994). So, if the model presented in Figure 8 is correct, the final $\mathrm{Ca}^{2+}$-dependent step during the first phase of release is probably different from that controlling the later phases. This might occur if vesicles docked at release sites could undergo exocytosis from one of two states: state 1 in which fusion requires $\mathrm{Ca}^{2+}$ to bind to a sensor of high affinity (or does not require $\mathrm{Ca}^{2+}$ at all), and state 2 in which fusion requires $\mathrm{Ca}^{2+}$ to bind a sensor of low affinity. If all docked vesicles were in state 2 after a period of rest, the first phase of exocytosis measured experimentally would have a requirement for high levels of $\mathrm{Ca}^{2+}$. But if vesicles arrived at release sites in state 1 , the continuous component of exocytosis would occur at lower $\mathrm{Ca}^{2+}$ concentrations. The idea of exocytosis from two different states is not new. In other neurons in which the kinetics of exocytosis have been characterized, the fast component of exocytosis synchronous with the action potential is followed by a slower asynchronous component that appears to be driven by residual $\mathrm{Ca}^{2+}$ (Zucker, 1989; Delaney and Tank, 1994; Goda and Stevens, 1994). Geppert et al. (1994) found that the synchronous component of exocytosis was blocked in hippocampal neurons cultured from mice in which synaptotagmin I had been knocked out, although the asynchronous component appeared intact.

At the moment, we do not have any information about the proteins that are involved in these vesicle movements, although Heidelberger (1998) has demonstrated that the hydrolysis of ATP is required for the refilling of the RRP in the terminal of bipolar cells.

\section{A comparison with other synapses}

The ribbon synapses of hair cells and photoreceptors also support continuous exocytosis at rates that indicate that release sites are efficiently replenished (Parsons et al., 1994; Rieke and Schwartz, 1996). Recently, Lenzi et al. (1999) used electron tomography to investigate the structure of ribbon synapses in saccular hair cells and found that it was not possible to reduce the number of ribbon-associated vesicles by continuous depolarization, leading to the conclusion that the transfer of vesicles to the ribbon was not rate-limiting during continuous exocytosis. It may therefore be that the $\mathrm{Ca}^{2+}$-dependent transport of vesicles through ribbons also occurs in hair cells.

In neurons that fire action potentials, residual $\mathrm{Ca}^{2+}$ accelerates recovery from synaptic depression after repetitive high-frequency stimulation (Dittman and Regehr, 1998; Stevens and Wesseling, 1998; Wang and Kaczmarek, 1998). This effect can be completely blocked by EGTA, which, as pointed out by Wang and Kaczmarek (1998), suggests that the reserve pool of vesicles is some way from the RRP. In contrast, EGTA did not inhibit the transfer of vesicles to the RRP at the ribbon synapse of bipolar cells (Figs. $6,7)$. This functional difference might reflect the introduction of lower concentrations of EGTA into the bipolar cell terminal, or it might be caused by the different anatomical arrangement of the reserve pool of vesicles in "classical" synapses and ribbon synapses. At a typical synapse in the CNS, there may be 100-200 vesicles per active zone, of which 10-20 may be docked, while the remainder form a cluster extending $\sim 500 \mathrm{~nm}$ from the presynaptic membrane in which they are linked to each other and the cytoskeleton (Burns and Augustine, 1995). At ribbon synapses, the reserve pool of vesicles appears to be more organized (Gray and Pease, 1971; Jacobs and Hudspeth, 1990; Rao-Mirotznik et al., 1995; Lenzi et al., 1999). In goldfish bipolar cells, vesicles dock to the plasma membrane in two rows of 11, on either side of the ribbon, and each face of the ribbon has approximately five rows of 11 vesicles attached by short filaments (von Gersdorff et al., 1996). The ribbon is only one vesicle diameter from the presynaptic membrane, and extends $\sim 150 \mathrm{~nm}$. This arrangement may hold vesicles of the reserve pool closer to the RRP and $\mathrm{Ca}^{2+}$ channels than is the case at other synapses.

\section{REFERENCES}

Betz WJ (1970) Depression of transmitter release at the neuromuscular junction of the frog. J Physiol (Lond) 206:629-644.

Burns ME, Augustine GJ (1995) Synaptic structure and function: dynamic organization yields architectural precision. Cell 83:187-194.

Burrone J, Lagnado L (1997) Electrical resonance and $\mathrm{Ca}^{2+}$ influx in the synaptic terminal of depolarizing bipolar cells from the goldfish retina. J Physiol (Lond) 505:571-584.

Del Castillo J, Katz B (1954) Quantal components of the end-plate potential. J Physiol (Lond) 124:560-573.

Delaney KR, Tank DW (1994) A quantitative measurement of the dependence of short-term synaptic enhancement on pre-synaptic residual calcium. J Neurosci 14:5885-5902.

Dittman JS, Regehr WG (1998) Calcium dependence and recovery kinetics of presynaptic depression at the climbing fiber to Purkinje cell synapse. J Neurosci 18:6147-6162.

Dowling JE, Ripps H (1973) Neurotransmission in the distal retina: the effect of magnesium on horizontal cell activity. Nature 242:101-103.

Geppert M, Goda Y, Hammer RE, Li C, Rosahl TW, Stevens CF, Sudhof TC (1994) Synaptotagmin I: a major $\mathrm{Ca}^{2+}$ sensor for transmitter release at a central synapse. Neuron 79:717-727.

Gillis KD (1995) Techniques for membrane capacitance measurements. In: Single channel recording (Sakmann B, Neher E, eds), pp 155-198. New York: Plenum.

Goda Y, Stevens CF (1994) Two components of transmitter release at a central synapse. Proc Natl Acad Sci USA 91:12942-12946.

Gray EG, Pease HC (1971) On understanding the organization of the retinal receptor synapses. Brain Res 35:1-15.

Heidelberger R (1998) Adenosine triphosphate and the late steps in calcium-dependent exocytosis at a ribbon synapse. J Gen Physiol 111:225-241.

Heidelberger R, Heinemann C, Neher E, Matthews G (1994) Calcium dependence of the rate of exocytosis in a synaptic terminal. Nature 371:513-515.

Jacobs RA, Hudspeth AJ (1990) Ultrastructural correlates of mechanoelectrical transduction in hair cells of the bullfrog's internal ear. Cold Spring Harb Symp Quant Biol 55:547-561.

Lagnado L, Gomis A, Job C (1996) Continuous vesicle cycling in the synaptic terminal of retinal bipolar cells. Neuron 17:957-967.

Lenzi D, Runyeon JW, Crum J, Ellisman MH, Roberts WM (1999) Synaptic vesicle populations in saccular hair cells reconstructed by electron tomography. J Neurosci 19:119-132.

Mennerick S, Matthews G (1996) Ultrafast exocytosis elicited by calcium current in synaptic terminals of retinal bipolar neurons. Neuron 17:1241-1249.

Neher E (1998) Vesicle pools and $\mathrm{Ca}^{2+}$ microdomains: new tools for understanding their roles in neurotransmitter release. Neuron 20:389-399.

Neher E, Marty A (1982) Discrete changes of cell membrane capacity observed under conditions of enhanced secretion in bovine adrenal chromaffin cells. Proc Natl Acad Sci USA 79:6712-6716.

Neves G, Lagnado L (1999) The kinetics of exocytosis and endocytosis in the synaptic terminal of goldfish retinal bipolar cells. J Physiol (Lond) 515:181-202.

Okada T, Horiguchi H, Tachibana M (1995) $\mathrm{Ca}^{2+}$-dependent $\mathrm{Cl}^{-}$current at the presynaptic terminals of goldfish retinal bipolar cells. Neurosci Res 23:297-303.

Parsons TD, Lenzi D, Almers W, Roberts WM (1994) Calciumtriggered exocytosis and endocytosis in an isolated presynaptic cell: capacitance measurements in saccular hair cells. Neuron 13:875-883. 
Rao-Mirotznik R, Harkins AB, Buchsbaum G, Sterling P (1995) Mammalian rod terminal: architecture of a binary synapse. Neuron $14: 561-569$.

Rieke F, Schwartz EA (1996) Asynchronous transmitter release: control of exocytosis and endocytosis at the salamander rod synapse. J Physiol (Lond) 493:1-8.

Rosenmund C, Stevens CF (1996) Definition of the readily releasable pool of vesicles at hippocampal synapses. Neuron 16:1197-1207.

Rouze NC, Schwartz EA (1998) Continuous and transient vesicle cycling at a ribbon synapse. J Neurosci 18:8614-8624.

Stevens CF, Wesseling JF (1998) Activity-dependent modulation of the rate at which synaptic vesicles become available to undergo exocytosis. Neuron 21:415-424.
Tachibana M, Okada T, Arimura T, Kobayashi K, Piccolino M (1993) Dihydropyridine-sensitive calcium current mediates neurotransmitter release from bipolar cells of the goldfish retina. J Neurosci 13:2898-2909.

von Gersdorff H, Matthews G (1994) Dynamics of synaptic vesicle fusion and membrane retrieval in synaptic terminals. Nature 367:735-739. von Gersdorff H, Vardi E, Matthews G, Sterling P (1996) Evidence that vesicles on the synaptic ribbon of retinal bipolar neurons can be rapidly released. Neuron 16:1221-1227.

Wang LY, Kaczmarek LK (1998) High-frequency firing helps replenish the readily releasable pool of synaptic vesicles. Nature 394:384-388.

Zucker RS (1989) Short-term synaptic plasticity. Annu Rev Neurosci $12: 13-31$ 